\title{
District Energy Systems: A Collaborative Exchange of Results on Planning, Operation and Modelling for Energy Efficiency ${ }^{+}$
}

Tatiana Loureiro ${ }^{1, *}$, Miika Rämä ${ }^{2}$, Raymond Sterling ${ }^{3}$, Marco Cozzini ${ }^{4}$, Meritxell Vinyals 5 , Michael Descamps ${ }^{5}$, Wolfgang Birk ${ }^{6}$, Gozde Unkaya ${ }^{7}$, Federica Fuligni ${ }^{7}$, Borna Doračić ${ }^{8}$, Marin Petrovic ${ }^{9}$, Dominik Rutz ${ }^{10}$, Inés Arias ${ }^{11}$, Sofia Lettenbichler ${ }^{11}$, Ioannis Meintanis ${ }^{12}$, Serafeim Moustakidis ${ }^{12}$, Martin Buchholz ${ }^{13}$, Reiner Buchholz ${ }^{14}$, Mathieu Provost ${ }^{14}$ and Philipp Geyer ${ }^{15}$

1 R2M Solution, Via Fratelli Cuzio 42, 27100 Pavia, Italy

2 VTT Technical Research Centre of Finland, Vuorimiehentie 3, 02150 Espoo, Finland; miika.rama@vtt.fi

3 NUIG,Department of Civil Engineering, University Road, H91 TK33 Galway, Ireland; raymond.sterling@nuigalway.ie

4 EURAC Research,Viale Druso 139100 Bolzano, Italy; marco.cozzini@eurac.edu

5 CEA, Gif-sur-Yvette CEDEX, 91191 Paris, France; meritxell.vinyals@cea.fr (M.V.); michael.descamps@cea.fr (M.D.)

6 Lulea University of Technology, Department of Computer Science, Electrical and Space Engineering, 97187 Luleå, Sweden; wolfgang.birk@ltu.se

7 Exergy, Coventry Innovation Village, CUTP, Cheetah Road, Coventry CV1 2TL, UK; gozdeunkaya@exergy-global.com (G.U.); ffuligni@exergy-global.com (F.F.)

8 University of Zagreb, Faculty of Mechanical Engineering and Naval Architecture, Ul. Ivana Lučića 5, 10000 Zagreb, Croatia; borna.doracic@fsb.hr (B.D.)

9 Municipality of Visoko, Alije Izetbegovića 12A, 71300 Visoko, Bosnia and Herzegovina; petrovic@mef.unsa.ba

10 WIP Renewable Energies, Sylvensteinstr. 2, 81369 Munich, Germany; dominik.rutz@wip-munich.de

11 DHC+ Technology Platform/Euroheat \& Power, Cours Saint Michel 30a-Box E, 1040 Brussels, Belgium; ia@euroheat.org (I.A.); sl@euroheat.org (S.L.)

12 City University of London, Systems \& Control Research Centre, Northampton Square, London EC1V 0HB, UK; ioannis.meintanis.1@city.ac.uk (I.M.); serafeim.moustakidis.1@city.ac.uk (S.M.)

13 Watergy, Oderberger st. 3, 10247 Berlin, Germany; martin.buchholz@watergy.de

14 TU Berlin, Institute for Energy Technology, Strasse des 17. Juni 135, 10623 Berlin, Germany; reiner.buchholz@tu-berlin.de (R.B.); mathieu.provost@tu-berlin.de (M.P.)

15 KU Leuven, Department of Architecture, Oude Markt 13-bus 5005, 3000 Leuven, Belgium; philipp.geyer@kuleuven.be

* Correspondence: tatiana.loureiro@r2msolution.com; Tel.: +39-0382-1726596

† Presented at Sustainable Places 2018 (SP2018), Aix-les Bains, France, 27-29 June 2018.

Published: 28 August 2018

Abstract: Workshop organized by INDIGO project as a collaborative activity among EU funded projects in the area of District Heating and Cooling. The objective of the workshop was twofold: (1) to create a cluster of European funded projects working in the area of District Energy Systems; and (2) to create a networking opportunity in which to share experiences on the results and difficulties of the researches, and to identify synergies.

Keywords: district energy systems; district heating and cooling; energy efficiency; planning; modelling 


\section{Introduction}

District Energy Systems: A collaborative exchange of results on planning, operation and modelling of energy efficiency, was a workshop within the Conference Sustainable Places 2018 aimed at clustering EU funded projects working with district heating and cooling in order to share the results of the projects and to identify synergies among the different researches.

This has been the second clustering workshop organized by INDIGO project within Sustainable Places. In 2017, the experience was interesting to introduce the projects existent in the area and to make contacts with the researchers, while this year the activity was focus on presenting specific results and to plan future collaborations.

\section{Presentations}

\subsection{INDIGO: "District Cooling Systems Planning Tool"}

The project INDIGO [1] focuses on district cooling by improving system planning, operation and control making them more efficient, intelligent and economic. As part of the project, an opensource planning tool for evaluating alternative district cooling system configurations, building and space-specific cooling systems is developed. The tool evaluates energy efficiency, economic performance and greenhouse gas emissions. User can quickly define an arbitrary system supported by pre-defined sets of input data. The tool then automatically generates an optimisation model representing the defined system and solves it, providing results for a representative year of operation. The model includes available resources, energy production and storage, cooling supply and distribution network. Finally, the results are processed to provide the user useful visualisations and set of key performance indicators.

\subsection{FLEXYNETS: "District Heating and Cooling with Distributed Heat Pumps"}

The FLEXYNETS project [2] proposes a district heating and cooling solution based on decentralized reversible heat pumps (HPs). The network is operated at neutral temperature, about $15-25{ }^{\circ} \mathrm{C}$, lowering thermal losses, facilitating the integration of low temperature waste heat, and giving rise to a reversible network, able to provide heating and cooling on the same pipes. HPs also enhance the link between thermal and electric sectors. The project includes 6 partners: EURAC (coordinator), Acciona, Enisyst, PlanEnergi, Soltigua, and the zafh.net institute of Stuttgart University. Simplified techno-economic estimates are combined with detailed simulations and laboratory experiments to identify feasible configurations and control solutions. The investigation of new business models-needed to deal with bi-directional energy flows and the combination of thermal and electric sources-is also included.

\subsection{PENTAGON: "Multi-Vector Energy Management Platform"}

The aim of the PENTAGON [3] multi-vector district energy management platform is to leverage the flexibility capabilities of energy storage and conversion technologies by enabling a district-level coordination of the three different energy carriers involved (thermal/electricity/gas). In particular, this presentation introduced the decentralised multi-vector flexibility optimization algorithm implemented to support the optimisation of districts involving the coordination of multiple stakeholders. The optimisation relies on a multi-agent system optimisation scheme that models the problem as an agent energy coordination network through which the different involved stakeholders autonomously coordinate by exchanging limited information (i.e., avoiding the privacy and interoperability issues caused by a centralised strategy). This platform will be tested on the experimental heating network at CEA-INES facilities.

\subsection{OPTi: "OPTi Framework for Increased Efficiency of DHC Systems"}

In this presentation the OPTi [4] Framework was summarized and explained how the different tools of the framework can be used to increase the efficiency of district heating and cooling (DHC) 
systems. OPTi's framework is composed of digital twin of a DHC system as the cornerstone, to evaluate new approaches for operating and optimizing the control of a DHC system. It was also discussed how consumer comfort zone estimations can be used to reduce energy usage, how forecasting can be used to use preheating and precooling in the peak load management, and how the control of distribution and substations can be improved.

\subsection{THERMOSS: "WARMe: Sizing Toolbox for Heating and Cooling Solutions"}

Thermoss [5] develops and implements high efficiency, low carbon heating and cooling technologies suitable for the EU market. Gas absorption and hybrid heat pumps, micro combined heat and power, and heat interface units have been available in the market for several years. However, their market uptake has been relatively slow, due to the lack of local installers and due to a number of operational difficulties faced by users. Thermoss assesses the needs of its end users in 6 different sites and makes necessary technical adjustments in order to minimise their operational costs, whilst maximising their whole life performance. In order to enable users to choose the most suitable heating and cooling technologies for their properties, Thermoss is developing a 'sizing toolbox', called WARMe. This tool allows users to estimate their annual gas and electricity consumption and identify the financially and environmentally feasible technologies.

\subsection{CoolHeating: "Small Renewable District Heating for South-Eastern Europe"}

District heating (DH) is unpopular in countries of South-Eastern Europe, mostly due to old and inefficient systems powered by fossil fuels. In contrast, new small renewable modular DH grids in communities have the potential to mitigate negative environmental impacts, while supplying heat at reasonable costs. This could improve the negative image on DH. However, the public opinion needs to be improved and policy makers need to be encouraged to support its market uptake. This is the main focus of the CoolHeating project [6]. The main outcomes of the project are individual technical concepts and business models for each of the five target cities in Slovenia, Croatia, Bosnia and Herzegovina, Serbia, and Macedonia. The results are disseminated to initiate renewable district heating investments in these countries.

\section{7. $\mathrm{SDHp} 2 \mathrm{~m}$}

SDHp2m [7] stands for 'Solar District Heating' and actions from 'Policy to Market'. The project addresses market uptake drivers and obstacles for a wider use of district heating and cooling systems (DHC) with high shares of renewable energy systems, focusing specifically on solar thermal energy. In 3 A-regions and 6 follower regions, common challenges for this emission-free, cost-stable and unlimitedly available renewable energy source are explored. They address available land (e.g., combined land use for solar thermal panels and agriculture), price competition, awareness raising, including subsidies, and administrative burdens.

Currently, the European market for solar DHC includes 300 plants and a nominal power of more than $350 \mathrm{kWth}$. The future for solar thermal DHC looks bright: The mean market growth over the last 5 years was 35\% annually and by 2050, 240 TWh are expected to be covered by solar thermal energy in DHC systems.

\subsection{PLANHEAT}

The PLANHEAT project [8] develops a tool to support local authorities in simulating and comparing low-carbon heating and cooling scenarios. By June 2018, the mapping module had been completed, while the planning and the simulation module are under development.

The mapping module can even be used with a minimum of available data. A top-down mapping approach (city assessment) where only data on final energy consumption and spatial indicators is needed and a bottom-up mapping (district assessment) with more detailed data on hourly values for optimisation can be performed. Also, the module allows to identify various renewable supply sources based on data from European databases. 
Three validation cities are constantly providing their feedback: Antwerp, Belgium; Lecce, Italy and Velika Gorica, Croatia. The project also supports 50 user cities in developing their heating and cooling plans with webinars and tutorials.

\subsection{InDeal: "Innovative Technology for District Heating and Cooling"}

The main objective of InDeal [9] is to transform current district heating and cooling systems (DHCS) into automated DHCS that will guarantee the increase of the overall energy efficiency of the system and a fairly distribution of heating and cooling based on the anticipated energy demand and network's efficiency. To accomplish this, an advanced automated Decision Support System is integrated with several innovative modules such as: (i) real-time energy consumption data gathering via artificial intelligent meters; (ii) predicting the weather conditions and energy needs; (iii) monitoring and control the level of energy stored in network's storage; (iv) solutions of minimizing heat losses via pipe design and innovative insulation materials.

A central control platform completes the solution and allows for 24/7 monitoring of the system.

\subsection{H-Disnet: "Thermo-Chemical Networks, Demand Side Application Demonstrators of the EU H2O2O H- DisNet Project"}

The H-Disnet project [10] develops solutions for capturing the major part of available waste/excess (temperatures less than $60^{\circ} \mathrm{C}$ ) heat with thermo-chemical systems. Excess heat is transformed to thermo-chemical potential by the use of desiccant brine solutions. This potential is stored, transported and finally exploited in thermo-chemical processes for drying, space heating and cooling at the demand-side. Heat of different temperature levels can be integrated within a hybrid network approach including thermal and thermos-chemical potentials. The presentation showed demand side applications at the project's demonstrators: A building prototype with applications of heating, latent heat recovery, humidity control, and cooling in Berlin and a greenhouse demonstrator with applications of indoor humidity control, heat recovery and cooling/dehumidification in Zürich.

Author Contributions: Writing-Original Draft Preparation, Review \& Editing, T.L.; 2.1 INDIGO, M.R. and R.S.; 2.2 FLEXYNETS, M.C.; 2.3 PENTAGON, M.V. and M.D.; 2.4 OPTi, W.B.; 2.5 THERMOSS, G.U. and F.F.; 2.6 CoolHeating, B.D., M.P. and D.R.; 2.7 SDHp2m, I.A.; 2.8 PLANHEAT, S.L.; 2.9 InDeal, I.M. and S.M.; 2.10 HDisnet, M.B., R.B., M.P. and P.G.

Funding: These researches were funded by European Union's Horizon 2020 research and innovation programme under Grant Agreements: New generation of Intelligent Efficient District Cooling Systems (INDIGO), GA \#696098; Market uptake of small modular renewable district heating and cooling grids for communities (CoolHeating), GA \#691679; Intelligent Hybrid Thermo-Chemical District Networks (H-DisNet), GA \#695780; BUILDING AND DISTRICT Thermal Retrofit and Management Solutions (THERMOSS), GA \#723562; Fifth generation, Low temperature, high EXergY district heating and cooling NETworkS (FLEXYNETS), GA \#649820; Unlocking European grid local flexibility through augmented energy conversion capabilities at district-level (PENTAGON), GA \#731125; Optimization of District Heating \& Cooling Systems (OPTi), GA \#649796; Integrated tool for empowering public authorities in the development of sustainable plans for low carbon heating and cooling (PLANHEAT), GA \#723757; Advanced policies and market support measures for mobilizing solar district heating investments in European target regions and countries (SDHp2m), GA \#691624; Innovative Technology for District Heating and Cooling (InDeal) GA \#696174.

\section{References}

1. INDIGO Website. Available online: http://indigo-project.eu/ (accessed on 25 July 2018).

2. FLEXYNETS Website. Available online: http://www.flexynets.eu/en/ (accessed on 25 July 2018).

3. PENTAGON Website. Available online: http://www.pentagon-project.eu/ (accessed on 25 July 2018).

4. OPTi Website. Available online: http://www.opti2020.eu/ (accessed on 25 July 2018).

5. THERMOSS Website. Available online: https://thermoss.eu/ (accessed on 25 July 2018).

6. CoolHeating Website. Available online: https://www.coolheating.eu/en/ (accessed on 25 July 2018).

7. SDHp2m in CORDIS website. Available online: https://cordis.europa.eu/project/rcn/199617_en.html (accessed on 25 July 2018). 
8. PLANHEAT website. Available online: http://planheat.eu/ (accessed on 25 July 2018).

9. InDeal Website. Available online: http://www.indeal-project.eu/ (accessed on 25 July 2018).

10. H-Disnet Website. Available online: https://www.h-disnet.eu/ (accessed on 25 July 2018).

(C) 2018 by the authors. Licensee MDPI, Basel, Switzerland. This article is an open access article distributed under the terms and conditions of the Creative Commons Attribution (CC BY) license (http://creativecommons.org/licenses/by/4.0/). 